\title{
Social, dietary and clinical correlates of oedema in children with severe acute malnutrition: a cross-sectional study
}

Maren Johanne Heilskov Rytter ${ }^{1,3^{*}}$, Hanifa Namusoke ${ }^{2}$, Esther Babirekere-Iriso ${ }^{2,3}$, Pernille Kæstel ${ }^{3}$, Tsinuel Girma ${ }^{3,4}$, Vibeke Brix Christensen ${ }^{1}$, Kim F Michaelsen ${ }^{3}$ and Henrik Friis ${ }^{3}$

\begin{abstract}
Background: Severe acute malnutrition is a serious public health problem, and a challenge to clinicians. Why some children with malnutrition develop oedema (kwashiorkor) is not well understood. The objective of this study was to investigate socio-demographic, dietary and clinical correlates of oedema, in children hospitalised with severe acute malnutrition.

Methods: We recruited children with severe acute malnutrition admitted to Mulago Hospital, Uganda. Data was collected using questionnaires, clinical examination and measurement of blood haemoglobin, plasma c-reactive protein and $a_{1}$-acid glycoprotein. Correlates of oedema were identified using multiple logistic regression analysis.

Results: Of 120 children included, 77 (64\%) presented with oedematous malnutrition. Oedematous children were slightly older (17.7 vs. 15.0 months, $p=0.006$ ). After adjustment for age and sex, oedematous children were less likely to be breastfed (odds ratio (OR): $0.19,95 \%$-confidence interval (CI): 0.06; 0.59), to be HIV-infected (OR: 0.10, $\mathrm{Cl}$ : 0.03; 0.41), to report cough (OR: $0.33, \mathrm{Cl}: 0.13 ; 0.82$ ) and fever (OR: $0.22, \mathrm{Cl}: 0.09 ; 0.51$ ), and to have axillary temperature $>37.5^{\circ} \mathrm{C}(\mathrm{OR}: 0.28 \mathrm{Cl}: 0.11 ; 0.68)$. Household dietary diversity score was lower in children with oedema (OR: 0.58, Cl: 0.40; 85). No association was found with plasma levels of acute phase proteins, household food insecurity or birth weight.

Conclusion: Children with oedematous malnutrition were less likely to be breastfed, less likely to have HIV infection and had fewer symptoms of other infections. Dietary diversity was lower in households of children who presented with oedema. Future research may confirm whether a causal relationship exists between these factors and nutritional oedema.
\end{abstract}

Keywords: Malnutrition, Kwashiorkor, Marasmus, Oedema, Breastfeeding, Diet, Infection, Acute phase proteins, Maternal deprivation

\section{Background}

Severe acute malnutrition (SAM) in children is a serious public health problem [1], and a challenge for clinicians [2]. SAM manifests as non-oedematous or oedematous malnutrition [3]. Oedematous malnutrition is an enigmatic and life-threatening condition, covering a clinical spectrum from simple nutritional oedema to fulminant

\footnotetext{
* Correspondence: marenrytter@hotmail.com

'Department of Paediatrics, Copenhagen University Hospital, Rigshospitalet, Blegdamsvej 9, 2100 Copenhagen, Denmark

${ }^{3}$ Department of Nutrition, Exercise and Sports, University of Copenhagen, Rolighedsvej 30, 1958 Frederiksberg C, Denmark

Full list of author information is available at the end of the article
}

kwashiorkor, with anaemia, hepatomegaly, mental changes and dermatosis, in addition to oedema. WHO currently define oedematous malnutrition by bilateral pitting oedema, regardless of whether other symptoms of kwashiorkor are present [4].

Although oedematous malnutrition was first described in scientific literature more than 80 years ago [5], the pathophysiology of the syndrome, and the mechanism behind the formation of oedema remains unknown [6]. Various explanations have been suggested: protein deficiency [7], hormonal imbalance [8], aflatoxin poisoning [9], and oxidative stress [10], but none have been 
verified, and a large intervention trial failed to prevent oedematous malnutrition with antioxidant supplements [11]. A retrospective study from Jamaica found higher birth weights in children with oedematous than non-oedematous malnutrition, and suggested pre-natal factors to influence the clinical phenotype of malnutrition [12].

One way to generate hypotheses about the causes of oedematous malnutrition is to assess how children with this condition differ from children with non-oedematous malnutrition in terms of socio-demographic background, clinical characteristics, and household diet. However, few previous studies have investigated this, with conflicting results, and with few exceptions [13], most were carried out in the last century, when diagnostic criteria for malnutrition differed from those used today.

The objective of this study was therefore to present an up-to-date investigation of socio-demographic, dietary and clinical correlates of oedema, in children hospitalised with SAM in a nutrition unit in Uganda.

\section{Methods \\ Study design}

This cross-sectional study is based on baseline data from a cohort study of children admitted for in-hospital treatment of SAM, between October 2012 and February 2013.

\section{Study site and standard treatment}

Mwanamugimu Nutrition Unit, Mulago Hospital, Uganda, is the main national rehabilitation centre for children with complicated SAM. Patients were treated following the Ugandan National Protocol for Integrated Management of Acute Malnutrition [14] using therapeutic diets, F75 and F100, and empiric parenteral antibiotics, followed by outpatient treatment with ready-to-use therapeutic food. At the time of the study, the outpatient clinic was only working one day per week, so referred children were not routinely assessed with appetite tests to determine whether they should receive in-patient or out-patient treatment. However, all admissions came through the hospitals acute care unit, meaning that all children had been evaluated sick enough to require hospital admission. All biological mothers were offered counselling and testing for HIV, following World Health Organization (WHO) guidelines [15]. If the mother was HIV-infected or absent, the child was tested.

\section{Inclusion and exclusion criteria}

Children were eligible if they were admitted on weekdays for treatment of SAM, defined as either weight-forheight $\mathrm{z}$-score $<-3$, using the WHO Growth Standard, or mid-upper arm circumference (MUAC) $<11.5 \mathrm{~cm}$, or bilateral pedal pitting oedema. Children had to be $6-59$ months old, live near the hospital, and their parent or guardian had to give informed consent. Children were excluded if they had significant disability (like cerebral palsy); shock or severe respiratory distress requiring resuscitation at admission; haemoglobin $<4 \mathrm{~g} / \mathrm{dl}$, or a body weight $<4.5 \mathrm{~kg}$.

\section{Questionnaire}

Caretakers were asked about the household where the child had lived during the two months preceding admission, about the child's breast-feeding history and symptoms present. Caretakers were asked to state which one of their child's symptoms they perceived as most severe. If the mother was present, she was asked to recall the child's birth weight.

Dietary data was collected by asking about whether seven types of high-quality foods were served in the household during the last two weeks (Additional file 1: Figure S1). The foods were locally available, but likely in limited amounts in resource-poor households. From this, a simple dietary diversity score (DDS) was calculated, as the sum of different food types served.

Food insecurity was evaluated using the validated Household Food Insecurity Access Scale (HFIAS) [16]. The scale consists of nine questions regarding perceived food insecurity, each with four frequency options, from "never" to "more than ten times in the past four weeks". A HFIAS score from 0-27 was calculated, and households classified as having no, mild, moderate, or severe food insecurity.

\section{Examinations}

On admission, oedema was diagnosed according to guidelines [17], and axillary temperature was measured. Anthropometric measurements were done by one nurse, trained in anthropometry, assisted by the child's caretaker. Measurements were done in triplicate, and the average of three measurements was used. Length was measured using an infant length board and MUAC using measuring tape, both to the nearest $1 \mathrm{~mm}$. Body weight was measured daily to the nearest $100 \mathrm{~g}$ using a digital scale. Anthropometric z-scores were computed in Stata using the command "zscore06" based on the 2006 WHO Growth Standards [18]. The lowest weight recorded during admission was used to compute z-scores for all children, to use the weight free from oedema. Maternal weight was measured using a digital scale with a precision of $100 \mathrm{~g}$ and height measured with a precision of $1 \mathrm{~mm}$ using a wall-mounted stadiometer. We did not by default remove extreme anthropometric values, but it was checked that they were likely to be real, by being present on different days, and by being in accordance with other measurements (e.g. those with extreme z-scores also had very low MUAC). To assess appetite, it was noted 
whether the child consumed all of the first served F75, or not.

\section{Blood samples}

On admission, haemoglobin was measured in venous blood collected in heparinized Vacutainer tubes, using HemoCue (Hb 201+, Ängelholm, Sweden). Plasma was obtained from a Vacutainer with citrate (Cell-Preparation Tube, Becton Dickinson, USA), stored at $-80 \mathrm{C}^{\circ}$, until shipped to Denmark on dry ice, where plasma (P-) level of C-reactive protein (CRP) and $\alpha_{1}$-acid glycoprotein (AGP) was measured at University of Copenhagen, Department of Nutrition, Exercise and Sports, with ABX Pentra 400 (Horiba, France).

\section{Ethical issues}

The study was approved by Makerere University School of Medicine's Research Ethics Committee, and Uganda National Council of Science and Technology. A consultative approval was obtained from the Danish National Board of Research Ethics. Parents or guardians willing to participate signed a written informed consent form, after oral and written information in English and Luganda. Participation in the study did not affect the medical and nutritional treatment, which was similar to that given to admitted children not included in the study.

\section{Statistics}

Data was double entered into EpiData (Odense, Denmark) and analysed using Stata 12 (StataCorp LP, College station, USA). To test differences in means between groups, $t$-tests were used for normally distributed variable, and for others (age, CRP, DDS and HFIAS score), Mann-Whitney ranksum-tests were used. Chi-square tests were used to test for differences in proportions between groups. For analysis of CRP, children were classified as having CRP levels above or below $10 \mathrm{mg} / \mathrm{L}$. The relationship between CRP and body temperature was examined with linear regression using the log-transformed CRP values. Correlates of oedema were identified using logistic regression, unadjusted and adjusted for sex and age in months, and results presented as odds ratios (OR) with 95\% confidence intervals (CI). Additionally, background and clinical characteristics were analysed adjusted for age, sex, HIV-status, and breastfeeding status. Dietary factors and food insecurity were also analysed adjusting for age, sex, breastfeeding status and for month of inclusion, to account for seasonality.

\section{Results}

Of 395 patients admitted to the unit during the study period, 120 (30\%) were included in the study (Figure 1). The reason for exclusion was known in 198 of nonincluded children, but unknown in 77 children. This could be due to insufficient completion of the screening log, or because some of these children were transferred from other hospital departments to MNU, and therefore missed screening. Among included children the median (range) age was 15.9 (6-53) months, and 62\% were boys. Almost half of the children's parents were not living together and $29(25 \%)$ of the children had not stayed with their mother during the preceding two months (Table 1).

\section{Clinical correlates of oedema}

Of the 120 included children, 77 (64\%) presented with oedematous malnutrition (Table 2), of which $6(8 \%)$ had grade 1 oedema (only feet), $22(28 \%)$ had grade 2 oedema (up to the knees), and 49 (64\%) had grade 3 oedema (above the knees). Oedematous children were slightly older than non-oedematous (17.7 vs. 15.0 months, $\mathrm{p}=0.006$ ). Seven percent of oedematous and $33 \%$ of nonoedematous children were still breastfed, and breastfeeding remained negatively associated with oedema, controlling for age and sex (OR: 0.19, CI: 0.06; 0.59).

More oedematous children had lived separated from their mother during the last two months (32\% vs. 14\%), but this difference was not significant when controlling for age and sex. There was no crude difference in height-for-age z-score (HAZ) between children with and without oedema. However, adjusting for age and sex, a

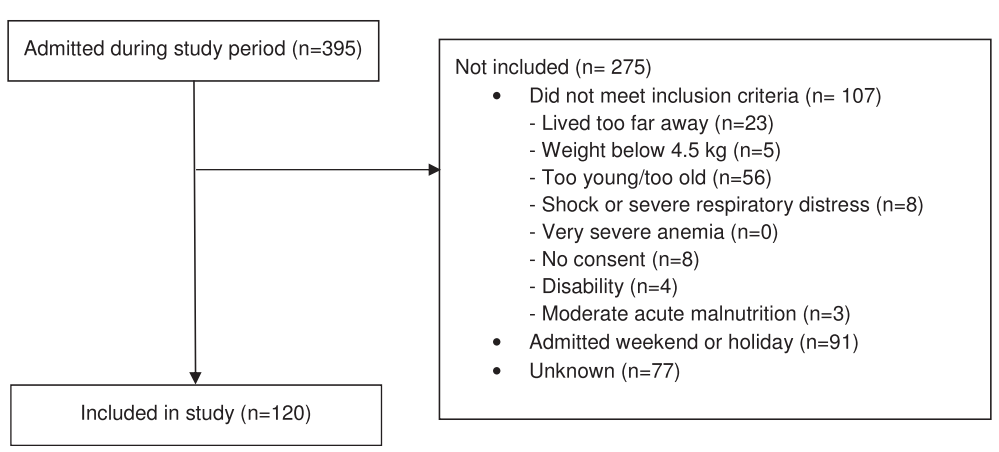

Figure 1 Flow diagram for inclusion into the study. 
Table 1 Background characteristics of 120 children admitted with severe acute malnutrition ${ }^{\text {a }}$

\begin{tabular}{lll}
\hline & $\mathbf{N}^{\mathbf{b}}$ & \\
\hline Female sex & 120 & $38(46)$ \\
Age, months & 120 & $15.9(12.6 ; 21.9)$ \\
$\begin{array}{l}\text { Mothers education attended } \\
\text { (not necessarily completed) }\end{array}$ & 97 & \\
$\quad$ No school & & $6(6)$ \\
$\quad$ Primary school & & $43(42)$ \\
$\quad$ Secondary school & & $43(42)$ \\
$\quad$ More than secondary school & & $7(7)$ \\
Household characteristics & 103 & $85(88)$ \\
Urban or peri-urban location & 93 & $14(13)$ \\
Occupation, head of household & & $9(8)$ \\
$\quad$ Unemployed & & $25(23)$ \\
$\quad \begin{array}{l}\text { Agriculture } \\
\text { Domestic service, unskilled manual } \\
\text { Skilled manual, sales and service } \\
\text { Professional/technical/management }\end{array}$ & & $39(36)$ \\
Drinking water available on premises & 107 & $20(21)$ \\
Improved, not shared, toilet facility & 94 & $18(17)$ \\
Household owns agricultural land & 109 & $36(39)$ \\
Household owns cattle & 105 & $6(6)$ \\
\hline
\end{tabular}

${ }^{\mathrm{a}}$ Values presented are $\%(\mathrm{~N})$, or median $(25 \% ; 75 \%) .{ }^{\mathrm{b}} \mathrm{N}=$ number of children in whom information was available.

positive association appeared between HAZ and oedema (OR: 1.47, CI: 1.05; 2.06). Children's birth weights were recalled by 88 mothers: it was $3.4 \mathrm{~kg}$ in oedematous and $3.5 \mathrm{~kg}$ in non-oedematous children, and not significantly different.

Among children with oedematous malnutrition, 8 (12\%) were HIV-infected, compared to 12 (31\%) of nonoedematous children, and HIV-infection remained less frequent in oedematous children when adjusting for age and sex (OR: 0.10, CI: 0.03; 0.41). Diarrhoea, cough and fever were reported in fewer oedematous children, and axillary temperature $>37.5^{\circ} \mathrm{C}$ was measured in $16 \%$ of oedematous children vs. $43 \%$ of non-oedematous children $(p=0.002)$. While no included children had hypothermia (axillary temperature $<35.5^{\circ} \mathrm{C}$ ), sub-normal axillary temperature $\left(<36.0^{\circ} \mathrm{C}\right)$ was seen in $12(16 \%)$ of oedematous children, and in no non-oedematous children $(p=0.008)$. Although a positive association was seen between body temperature and CRP $(\beta=0.18, p=0.04)$, the three children with the highest CRP values all had normal body temperature. We did not find any indications that the association between CRP and body temperature was different in oedematous and non-oedematous children. The symptom causing greatest worry to caretakers of oedematous children was "swelling" (61\%), followed by "diarrhoea" (11\%), while caretakers of non-oedematous children were most concerned about "diarrhoea" (29\%), "weight loss" (24\%), and "fever" (11\%) (Table 3). Eightythree percent of oedematous and $69 \%$ of non-oedematous children were able to consume all their first served F75, and thus, observed appetite was marginally better in oedematous children (OR: 2.55, CI: 0.89; 7.30).

Sixty-seven percent of oedematous, and $77 \%$ of nonoedematous children had CRP $>10 \mathrm{mg} / \mathrm{l}$, which was not significantly different, and neither were AGP or haemoglobin levels.

\section{Maternal data, household diet and food insecurity in association with oedema}

Oedematous children came from larger households than non-oedematous children (Table 4). Of seven specific food types served in the household, nuts and fresh fruit were significantly less frequently served in households of oedematous children. There was also a trend for lower household consumption of fish and green leafy vegetables in oedematous children, although not significantly so. Total dietary diversity, obtained by adding up the number of different food types served, was negatively associated with oedema (OR: 0.58, CI: 0.40; 0.85), while food insecurity measured as HFIAS score was not.

\section{Further adjusted analyses}

In order to investigate whether any of the observed associations could be explained by HIV-infection or breastfeeding, we did further analyses adjusted for age, sex, HIV status and current breastfeeding (not shown in table). In this model, HIV-status and current breastfeeding were still negatively associated with oedema (HIV status: OR: 0.10, CI: 0.02; 0.50, breastfeeding OR: 0.24, CI: $0.02 ; 0.50)$, and age positively associated with oedema (OR 1.13, CI: 1.03; 1.23). Reported cough, diarrhoea and fever also remained negatively associated with oedema (cough: OR 0.13, CI: 0.03; 0.48, diarrhoea: OR: 0.32, CI: 0.11; 0.89, fever: OR: 0.15, CI: $0.05 ; 0.44)$, and so did elevated temperature measured on admission (OR 0.25, CI: $0.09 ; 0.73)$.

In contrast, appetite on admission was not associated with oedema when adjusting for age, sex, HIV-status and breastfeeding (OR: 2.13, CI: 0.56; 7.90), and neither was separation from the mother, household size, or having a pregnant mother or younger sibling.

We also analysed the data on household diet and food insecurity adjusting for age, sex, breastfeeding and month of the study, to account for seasonality. This did not change any of the observed associations.

\section{Discussion}

Few studies have compared characteristics of children with nutritional oedema, to children with non-oedematous 
Table 2 Clinical and biochemical correlates of oedema among 120 children with severe acute malnutrition on hospital admission

\begin{tabular}{|c|c|c|c|c|c|c|}
\hline & & Oedema $^{a}$ & No oedema ${ }^{a}$ & & Odds Ratio (95 & \\
\hline & $\mathbf{N}^{\mathrm{c}}$ & $\mathrm{n}=77$ & $n=43$ & p & & $\mathbf{p}$ \\
\hline Female sex & 120 & $36(28)$ & $42(18)$ & 0.55 & $0.85(0.38 ; 1.86)$ & 0.68 \\
\hline Age, months & 120 & $17.7(13.5 ; 23.3)$ & $15.0(10.5 ; 19.5)$ & 0.006 & $1.06(1.01 ; 1.12)$ & 0.03 \\
\hline Currently breastfed & 111 & $7(5)$ & $33(14)$ & $<0.001$ & $0.19(0.06 ; 0.59)$ & 0.004 \\
\hline Lived with mother last two months & 114 & $68(49)$ & $86(36)$ & 0.04 & $0.42(0.15 ; 1.17)$ & 0.10 \\
\hline Anthropometric data & & & & & & \\
\hline Mid-upper arm circumference, $\mathrm{cm}$ & 117 & $12.1 \pm 1.4$ & $10.6 \pm 0.6$ & $<0.0001$ & $3.72(2.18 ; 6.35)$ & $<0.001$ \\
\hline Weight-for-height, $z^{\mathrm{d}}$ & 120 & $-3.0 \pm 1.4$ & $-4.1 \pm 1.0$ & $<0.0001$ & $2.10(1.43 ; 3.08)$ & $<0.001$ \\
\hline Height-for-age, Z & 120 & $-3.1 \pm 1.4$ & $-3.2 \pm 1.5$ & 0.58 & $1.47(1.05 ; 2.06)$ & 0.03 \\
\hline Recalled birth weight, $\mathrm{kg}^{\mathrm{e}}$ & 88 & $3.4 \pm 0.9$ & $3.5 \pm 0.9$ & 0.53 & $0.84(0.51 ; 1.39)$ & 0.49 \\
\hline Child's clinical data & & & & & & \\
\hline HIV-infected children & 104 & $12(8)$ & $31(12)$ & 0.02 & $0.10(0.03 ; 0.41)$ & 0.001 \\
\hline Reported symptoms on admission & & & & & & \\
\hline Diarrhoea & 112 & $43(17)$ & $63(25)$ & 0.04 & $0.45(0.20 ; 1.02)$ & 0.06 \\
\hline Cough & 112 & $54(39)$ & $78(31)$ & 0.02 & $0.33(0.13 ; 0.82)$ & 0.02 \\
\hline Fever & 112 & $26(19)$ & $65(26)$ & $<0.001$ & $0.22(0.09 ; 0.51)$ & $<0.001$ \\
\hline Axillary temperature $>37.5^{\circ} \mathrm{C}$ & 116 & $16(12)$ & $43(18)$ & 0.002 & $0.28(0.11 ; 0.68)$ & 0.005 \\
\hline Axillary temperature $<36.0^{\circ} \mathrm{C}$ & 116 & $16(12)$ & $0(0)$ & 0.006 & -9 & - \\
\hline Observed appetite $^{f}$ & 95 & $83(52)$ & $69(22)$ & 0.13 & $2.55(0.89 ; 7.31)$ & 0.08 \\
\hline Biochemical data on admission & & & & & & \\
\hline Plasma c-reactive protein, mg/L & 83 & $17.9(6.2 ; 32.7)$ & $20.0(12.1 ; 42.3)$ & 0.51 & $0.99(0.98 ; 1.00)$ & 0.28 \\
\hline$>10 \mathrm{mg} / \mathrm{L}$ & & $67(38)$ & $77(20)$ & 0.35 & $0.48(0.16 ; 1.43)$ & 0.19 \\
\hline Plasma $a_{1}$-acid glycoprotein, g/L & 83 & $2.46 \pm 0.62$ & $2.26 \pm 0.92$ & 0.26 & $1.35(0.70 ; 2.60)$ & 0.38 \\
\hline Haemoglobin, g/dL & 112 & $8.9 \pm 2.2$ & $9.2 \pm 2.5$ & 0.46 & $0.98(0.82 ; 1.17)$ & 0.82 \\
\hline
\end{tabular}

${ }^{a}$ Values presented are $\%(n)$, median $(25 \% ; 75 \%)$ or mean $\pm S D ;{ }^{b}$ Odds ratio calculated by logistic regression, adjusted for age and sex; ${ }^{c} \mathrm{~N}=$ number of children for whom information is available; ${ }^{d}$ Z-scores were computed based on the lowest weight recorded (after loss of oedema), for all children; ${ }^{e}$ Only asked if mother was present; ${ }^{\mathrm{f}}$ Noted if the child was able to consume all of the first serving of F75; ${ }^{9}$ Cannot be estimated since no non-oedematous children had temperature $<36.0^{\circ} \mathrm{C}$.

Table 3 The single symptom causing greatest worry to caretakers of oedematous and non-oedematous children, respectively $^{\mathrm{a}}$

\begin{tabular}{llll}
\hline & $\begin{array}{l}\text { Oedema } \\
\mathbf{n = 7 1}\end{array}$ & $\begin{array}{l}\text { No oedema } \\
\mathbf{n}=\mathbf{3 8}\end{array}$ & $\mathbf{p}$ \\
\hline $\begin{array}{l}\text { Symptom } \\
\text { Swelling }\end{array}$ & $61(43)$ & $8(3)$ & $<0.001$ \\
Diarrhoea & $11(8)$ & $29(11)$ & \\
Weight loss & $4(3)$ & $24(9)$ & \\
Fever & $6(4)$ & $10(4)$ & \\
Lack of appetite & $3(2)$ & $10(4)$ & \\
Vomiting & $4(3)$ & $5(2)$ & \\
Cough/difficulty breathing & $3(2)$ & $8(3)$ & \\
Rash & $4(3)$ & $3(1)$ & \\
Other & $4(3)$ & $3(1)$ & \\
\hline
\end{tabular}

${ }^{a}$ Data presented are \% (n).
SAM. In our study, children with oedema were less likely to be breastfed, less likely to have HIV infection, reported fewer symptoms of infections and had higher HAZ, and the dietary diversity was lower in families of children who presented with oedema.

\section{Breastfeeding}

Oedematous children were less likely to be breastfed, even after adjusting for age. Separation from the mother had more frequently occurred in children with oedematous malnutrition, and their mothers were more frequently pregnant or had given birth to a younger sibling, but both of these associations seemed mediated by lack of breastfeeding. The association with breastfeeding seemed to be independent of the association with HIV.

In Luganda, the main language spoken in Kampala, oedematous malnutrition is called obwoosi which means 
Table 4 Maternal and household data, household diet and food insecurity and their association with oedema among 120 children with severe acute malnutrition

\begin{tabular}{|c|c|c|c|c|c|c|}
\hline & & Oedema $^{a}$ & No oedema ${ }^{a}$ & & Odds Ratio $(95 \% \mathrm{Cl})^{\mathrm{b}}$ & \\
\hline & $\mathrm{N}^{\mathrm{c}}$ & $\mathrm{n}=77$ & $n=43$ & $\mathbf{p}$ & & $\mathbf{p}$ \\
\hline \multicolumn{7}{|l|}{ Maternal and household data } \\
\hline Mothers body-mass index, $\mathrm{kg} / \mathrm{m}^{2}$ & 81 & $21.8 \pm 2.9$ & $21.3 \pm 2.0$ & 0.45 & $1.09(0.91 ; 1.31)$ & 0.36 \\
\hline Mother living with child's father & 116 & $52(38)$ & $56(24)$ & 0.70 & $0.88(0.41 ; 1.92)$ & 0.75 \\
\hline Mother pregnant or has younger child & 102 & $22(14)$ & $8(3)$ & 0.08 & $2.83(0.74 ; 10.8)$ & 0.13 \\
\hline Number of people in household & 113 & $5.6 \pm 2.5$ & $4.5 \pm 1.7$ & 0.008 & $1.33(1.06 ; 1.67)$ & 0.01 \\
\hline \multicolumn{7}{|l|}{ Foods served in household last two weeks ${ }^{d}$} \\
\hline Fish & 100 & $55(33)$ & $73(29)$ & 0.08 & $0.42(0.17 ; 1.02)$ & 0.06 \\
\hline Nuts & 97 & $83(49)$ & $95(36)$ & 0.09 & $0.17(0.03 ; 0.88)$ & 0.03 \\
\hline Eggs & 98 & $51(30)$ & $49(19)$ & 0.84 & $1.22(0.52 ; 2.88)$ & 0.65 \\
\hline Meat & 99 & $72(43)$ & $67(26)$ & 0.60 & $1.16(0.46 ; 2.91)$ & 0.75 \\
\hline Dairy products & 97 & $66(39)$ & $82(31)$ & 0.10 & $0.38(0.14 ; 1.08)$ & 0.07 \\
\hline Green leafy vegetables & 94 & $71(40)$ & $84(32)$ & 0.15 & $0.34(0.11 ; 1.04)$ & 0.06 \\
\hline Fresh fruits & 98 & $73(44)$ & $87(33)$ & 0.11 & $0.26(0.08 ; 0.87)$ & 0.03 \\
\hline Dietary Diversity Score, $0-7^{e}$ & 90 & $5(4 ; 6)$ & $6(5 ; 6)$ & 0.02 & $0.58(0.40 ; 0.85)$ & 0.005 \\
\hline \multicolumn{7}{|l|}{ Household Food Insecurity ${ }^{d}$} \\
\hline Household Food Insecurity Access Scale Score, 0 -27 & 93 & $5.0(0.0 ; 10.0)$ & $8.5(1.5 ; 15.5)$ & 0.15 & $0.97(0.91 ; 1.03)$ & 0.34 \\
\hline Food insecurity category & 97 & & & 0.07 & & \\
\hline Food secure & & $32(19)$ & $21(8)$ & & ref. & \\
\hline Mildly food insecure & & $8(5)$ & $5(2)$ & & $0.72(0.10 ; 5.48)$ & 0.75 \\
\hline Moderately food insecure & & $29(17)$ & $16(6)$ & & $1.37(0.37 ; 5.10)$ & 0.64 \\
\hline Severely food insecure & & $31(18)$ & $58(22)$ & & $0.35(0.12 ; 1.04)$ & 0.06 \\
\hline
\end{tabular}

${ }^{a}$ Values presented are $\%(n)$, median $(25 \% ; 75 \%)$ or mean $\pm S D ;{ }^{b}$ Odds ratio calculated by logistic regression, adjusted for age and sex; ${ }^{c} n=$ number of children for whom information is available; ${ }^{d}$ Only caretakers who had stayed with the child during the last two weeks were asked; ${ }^{\text {e }}$ Sum of different food types (listed above) served in household during last two weeks.

"the child has a pregnant mother". Here, it is common practice to separate children from their pregnant mothers, causing abrupt weaning from breast milk (Esther Babirekere, personal communication, 2014). The term kwashiorkor was translated by Williams in 1935, as "the disease the disposed baby gets when the next is born". She noted an association with an absent or sick mother, and lack of breastfeeding [19]. Later, other studies reported oedematous malnutrition to occur in breastfed children as well, leading the authors to question whether breastfeeding is indeed protective [20]. A study from Sudan found no difference in breastfeeding practice in children with different types of malnutrition [21], while studies from Lesotho [22] and Nigeria [23] found less breastfeeding in oedematous children, although no adjustments were made for the higher age of oedematous children.

Breastfeeding may protect against oedematous malnutrition by nutritional, immunological, microbial or social mechanisms. It is unknown whether certain nutrients are particularly deficient in oedematous malnutrition, but if so, it could be something usually provided in sufficient amounts in breast milk. Breast milk also contains immune modulating substances, and immunological mechanisms have been suggested to be involved in the pathogenesis of oedematous malnutrition [24]. Breastfed children have a different gut microbial flora from non-breastfed, which could also be a mechanism [25]. Finally, breastfeeding may be a marker of attachment between child and mother, and associated with maternal care and stimulation, and older studies have indeed hypothesized that emotional deprivation and abrupt breaking of the motherinfant bond could play a role in the development of oedematous malnutrition [26]. In our study, living away from the mother was no longer associated with oedema when breastfeeding was controlled for; however, disentangling the nutritional and social aspects of breastfeeding is difficult, and we cannot rule out that emotional or social factors are involved in a protective effect of breastfeeding against oedematous malnutrition. 


\section{Infections}

In agreement with other studies [24,27], we found that fewer oedematous children were HIV-infected. Oedematous children also had less caregiver-reported symptoms of infection, and less frequent measured temperature $>37.5^{\circ} \mathrm{C}$, associations that did not seem to be explained by the children's HIV-status.

Malnutrition is often precipitated by infection [28], however, the pattern of infection in the two types of malnutrition has not received much attention. Our group recently reported more infections in nonoedematous children from a similar setting in Ethiopia [13]; more diarrhoea in non-oedematous children was reported from Kenya [29], while another Ugandan study found similar rates of bacteraemia in the two types of malnutrition [30]. These observations somewhat question the paradigm of oedematous malnutrition being particularly triggered by infections, which initiated the theory of oxidative stress causing oedematous malnutrition [10]. This theory has already been challenged by the results of a large randomized controlled trial which failed to prevent oedematous malnutrition in susceptible children with anti-oxidant supplements [11]. We also found that appetite was not significantly different and, if anything, poorer in non-oedematous children, also challenging the classical idea of oedematous malnutrition being particularly associated with anorexia, although the appetite recorded was simply whether or not the child completed its first feed of F75.

However, this pattern of infection could be explained by care-seeking behaviour of parents and clinicians: It seems plausible that a caretaker would seek help for a child with oedema, regardless of what other symptoms the child may have. In contrast, a parent may not necessarily seek help for a child who is thin, unless other symptoms develop. A hospital setting may therefore select non-oedematous children with co-infections, but not necessarily oedematous children with coinfections. This explanation is supported by answers to the question: "what symptom worries you most?". Caretakers of children with oedema most frequently responded "body swelling", while caretakers of nonoedematous most frequently responded "diarrhoea". Plausibly, this pattern of infection could be different if malnourished children were identified by community screening.

In contrast to reported symptoms of infection, we found no association between oedema and P-CRP and P-AGP, and the association between elevated acute phase reactants and clinical signs of infections was not very strong. Possibly, some reported symptoms were not caused by bacterial infections, or some children were not mounting a febrile response despite being infected.

\section{Household dietary diversity}

We found that oedematous children came from households with a less diverse diet. For nuts and fresh fruits we found significant negative associations with oedema, while marginally significant associations were seen with fish, dairy products and green leafy vegetables. Since a sick child's recent diet may be considerably different from the diet that lead to malnutrition, and recalling the pre-morbid diet is likely to be unreliable, we considered that household diet would give the most adequate picture of the child's dietary environment. The lower dietary diversity in households of oedematous children was apparently not explained by higher degree of food insecurity.

A few other studies have investigated diets in relation to oedematous malnutrition, and remarkably few specific dietary risk factors have been identified [21,28,31]. The idea that oedematous malnutrition was caused by dietary protein deficiency was challenged when studies from India and Nigeria found no difference in dietary protein between children with oedematous and non-oedematous malnutrition [23,32]. One study, using an indirect method similar to ours, found that siblings to children with oedematous malnutrition consumed less tomato and eggs [31]. In contrast, a prospective study among atrisk children did not identify any single food item protecting against oedematous malnutrition, neither was the dietary diversity lower in those who developed oedematous malnutrition. However, in their DDS, foods in three of the seven food groups were virtually never consumed by the population, and while our score was based on diet during two weeks, theirs was based on diet consumed in one day [28]. While using food consumed during one day may be more specific when the diet is generally diverse, it is possible that comparing diet consumed over a longer period is more informative in populations consuming a very monotonous diet. Although we are not able to suggest any specific nutrient or food item that is lacking in the diet of children with oedematous malnutrition, our results suggest that it may indeed be worthwhile to examine the pre-morbid diet of these children, and that total dietary diversity, or the opposite, diet monotony, may be important for development of oedematous malnutrition.

\section{Birth weight and stunting}

We found no association between recalled birth weight and oedema. Accordingly, our data contradict a recent report of higher birth weights in children with oedematous malnutrition [12]. With birth weight data available for only 88 we may have had insufficient power to detect a difference; however, we did not even see a trend for higher birth-weights in oedematous children. A reason for the discrepancy could be that the other 
study included children with non-oedematous SAM based on weight-for-age, which will inherently include more low-birth-weight children, while we included based on weight-for-height $\mathrm{z}$-score and MUAC, less likely to select low-birth-weight children. However, our data should be interpreted with caution, being based on maternal recall; more than half reported a weight where the first decimal was 0 or 5 (e.g. $3.0 \mathrm{~kg}$ or $2.5 \mathrm{~kg}$ ), indicating that their recall was imprecise.

Although children with the two types of malnutrition had similar HAZ, the non-oedematous were most stunted, adjusting for age. Children in our cohort, and elsewhere [33], tend to get progressively stunted with age; this explains how oedematous children with similar HAZ were less stunted, relative to their older age. An interpretation of this could be that oedematous children had been malnourished for a shorter time, or that non-oedematous children had been affected by more infections, which is known to cause stunting.

There are several limitations to our study: First, the observational and cross-sectional design precludes us from drawing conclusions about causality. However, by identifying associations we may formulate hypotheses, and later, in prospective studies test whether nonbreastfed children, and children from households with low dietary diversity are indeed more likely to develop oedematous malnutrition. Second, some of the indicators used, like the DDS and the measure of appetite, were developed for the study, and have not been previously validated. Third, the exploratory nature of our study means that we make a considerable number of statistical tests. With the cut-off chosen for significance $(\mathrm{p}<0.05)$ some of our findings are likely caused by chance. Since we did not adjust for multiple testing, our finding should be confirmed in other cohorts. On the other hand, some non-significant associations could be due to low power, with only 120 children included in our study.

\section{Conclusion}

Breastfeeding, dietary diversity and infections were negatively associated with oedema in hospitalised children with SAM. Whether these factors play a causal role in the development of specific types of malnutrition remain unknown. Prospective studies among at-risk children are recommended to determine whether the factors are present before malnutrition develops, and whether the associations are also present in children in the community, not recruited from a hospital setting. It is possible, that clinical signs of infections may indicate different conditions than acute phase reactants, which should also be addressed in future studies.

\section{Additional file}

Additional file 1: Figure S1. Dietary Diversity Questionnaire used in data collection.

\section{Abbreviations}

AGP: a-1 acid glycoprotein; Cl: 95\% confidence interval; CRP: C-reactive protein; DDS: Dietary diversity score; HAZ: Height-for-age z-score; HIV: Human immunodeficiency virus; HFIAS: Household food insecurity access scale; MUAC: Mid-upper-arm circumference; OR: Odds ratio; SAM: Severe acute malnutrition; WHO: World Health Organization.

\section{Competing interests}

The authors declare that they have no competing interests.

\section{Authors' contributions}

MJHR conceptualized and designed the study, supervised data collection, analysed the data, and drafted the initial manuscript and approved the final manuscript as submitted. HN conceptualized and designed the study, supervised data collection, reviewed and revised the manuscript and approved the final manuscript as submitted. HF and TG conceptualized and designed the study, reviewed and revised the manuscript and approved the final manuscript as submitted. EB collected data for the study, reviewed and revised the manuscript and approved the final manuscript as submitted. PK conceptualized and designed the study, contributed to analysis and interpretation of data, reviewed and revised the manuscript and approved the final manuscript as submitted. VBC and KFM contributed to interpretation of data, reviewed and revised the manuscript and approved the final manuscript as submitted. All authors read and approved the final manuscript.

\section{Acknowledgements}

We are grateful to Dr. Elizabeth Kiboneka, head of Mwanamugimu Nutrition Unit, for facilitating the study, supervision and guidance; to Anne-Louise Hother Nielsen and Christian Ritz for assisting with data analysis; to Sofine Heilskov, Amira Catharina Khattar Sørensen, Kia Hee Schultz and Charlotte Gylling Mortensen for data collection, and to Julian Eyotaru, Loice Atuhaire, Susan Awori, Justine Naggayi and Joseph Mbabazi for data collection and skilled care of our patients. The study was funded by a PhD grant from University of Copenhagen, and received support from Augustinus Fonden, Lundbeck Fonden, Brødrene Hartmanns Fond, Arvid Nielsens Fond, Axel Muusfeldts Fond, Aase and Einar Danielsens Fond and Torkild Steenbecks Legat. The funding sources had no influence on design of the study, data collection and analysis, or interpretation of the results.

\section{Author details}

'Department of Paediatrics, Copenhagen University Hospital, Rigshospitalet, Blegdamsvej 9, 2100 Copenhagen, Denmark. ${ }^{2}$ Mwanamugimu Nutrition Unit, Department of Paediatrics, Mulago Hospital, Kampala, Uganda. ${ }^{3}$ Department of Nutrition, Exercise and Sports, University of Copenhagen, Rolighedsvej 30 1958 Frederiksberg C, Denmark. ${ }^{4}$ Department of Paediatrics and Child Health, Jimma University Specialized Hospital, Jimma, Ethiopia.

Received: 21 October 2014 Accepted: 4 March 2015

Published online: 22 March 2015

\section{References}

1. Black RE, Victora CG, Walker SP, Bhutta ZA, Christian P, de Onis M, et al. Maternal and child undernutrition and overweight in low-income and middle-income countries. Lancet. 2013;382:427-51.

2. WHO. Updates on the management of severe acute malnutrition in children Guideline. Geneva: WHO; 2013.

3. World Health Organization, United Nations Children's Fund. WHO child growth standards and the identification of severe acute malnutrition in infants and children A Joint Statement. Geneva: WHO; 2009.

4. WHO. Pocket Book of Hospital Care for Children. 2nd edition. WH0. 2013

5. Williams CD. A nutritional disease of childhood associated with a maize diet. Arch Dis Child. 1933;8:423-33.

6. Briend A. Kwashiorkor: still an enigma - the search must go on. CMAM Forum Technical Brief. 2014. 
7. Waterlow JC. Protein Energy Malnutrition, vol. 1992. 2nd ed. London: Hodder \& Stouton; 1992.

8. Whitehead RG, Lunn PG. Endocrines in protein-energy malnutrition. Proc Nutr Soc. 1979:38:69-76.

9. Hendrickse RG, Coulter JB, Lamplugh SM, MacFarlane SB, Williams TE, Omer $\mathrm{Ml}$, et al. Aflatoxins and kwashiorkor. Epidemiology and clinical studies in Sudanese children and findings in autopsy liver samples from Nigeria and South Africa. Bull Soc Pathol Exot Ses Fil. 1983;76:559-66.

10. Golden $M H$, Ramdath D. Free radicals in the pathogenesis of kwashiorkor. Proc Nutr Soc. 1987:46:53-68.

11. Ciliberto $H$, Ciliberto M, Briend A, Ashorn P, Bier D, Manary M. Antioxidant supplementation for the prevention of kwashiorkor in Malawian children: randomised, double blind, placebo controlled trial. BMJ. 2005;330:1109.

12. Forrester TE, Badaloo AV, Boyne MS, Osmond C, Thompson D, Green C, et al. Prenatal factors contribute to the emergence of kwashiorkor or marasmus in severe undernutrition: evidence for the predictive adaptation model. PLoS One. 2012;7:e35907.

13. Girma T, Kæstel P, Mølgaard C, Michaelsen KF, Hother A-L, Friis H. Predictors of oedema among children hospitalized with severe acute malnutrition in Jimma University Hospital, Ethiopia: a cross sectional study. BMC Pediatr. 2013;13:204.

14. Ministry of Health, Uganda. Integrated Management of Acute Malnutrition Guidelines. Kampala: MoH; 2010.

15. WHO. Service delivery approaches to HIV testing and counselling (HTC): a strategic HTC policy framework. Geneva: WHO; 2012.

16. Coates J, Swindale A, Bilinsky P. Household Food Insecurity Access Scale (HFIAS) for Measurement of Food Access: Indicator Guide. Washongton DC: FANTA; 2007.

17. Ann Ashworth/WHO. Guidelines for the inpatient treatment of severely malnourished children. Generva, WHO, 2003 http://whqlibdoc.who.int/ publications/2003/9241546093.pdf?ua=1\&ua=1

18. WHO Multicentre Growth Reference Study Group. WHO Child Growth Standards based on length/height, weight and age. Acta Paediatr Suppl. 2006;450:76-85.

19. Williams C. Kwashiorkor - a nutritional disease in children associated with a maize diet. The Lancet. 1935;226:1151-115.

20. Golden MH. Protein deficiency, energy deficiency, and the oedema of malnutrition. Lancet. 1982;1:1261-5.

21. Coulter JB, Omer MI, Suliman Gl, Moody JB, Macfarlane SB, Hendrickse RG. Protein-energy malnutrition in northern Sudan: prevalence, socio-economic factors and family background. Ann Trop Paediatr. 1988;8:96-102.

22. Tolboom JJ, Ralitapole-Maruping AP, Kabir H, Molatseli P, Anderson J. Severe protein energy malnutrition in Lesotho, conditioning factors and death and survival in hospital. Trop Geogr Med. 1989;41:1-8.

23. Laditan AA, Reeds PJ. A study of the age of onset, diet and the importance of infection in the pattern of severe protein-energy malnutrition in Ibadan, Nigeria. Br J Nutr. 1976;36:411-9.

24. Bachou H, Tylleskär T, Downing R, Tumwine JK. Severe malnutrition with and without HIV-1 infection in hospitalised children in Kampala, Uganda: differences in clinical features, haematological findings and CD4+ cell counts. Nutr J. 2006;5:27-7.

25. Bergström A, Skov TH, Bahl Ml, Roager HM, Christensen LB, Ejlerskov KT, et al. Establishment of intestinal microbiota during early life: a longitudinal, explorative study of a large cohort of Danish infants. Appl Environ Microbiol. 2014;80:2889-900.

26. Goodall J. A social score for kwashiorkor: explaining the look in the child's eyes. Dev Med Child Neurol. 1979;21:374-84.

27. Fergusson P, Chinkhumba J, Grijalva-Eternod C, Banda T, Mkangama C, Tomkins A. Nutritional recovery in HIV-infected and HIV-uninfected children with severe acute malnutrition. Arch Dis Child. 2009:94:512-6.

28. Lin CA, Boslaugh S, Ciliberto HM, Maleta K, Ashorn P, Briend A, et al. A prospective assessment of food and nutrient intake in a population of Malawian children at risk for kwashiorkor. J Pediatr Gastroenterol Nutr. 2007:44:487-93.

29. Talbert A, Thuo N, Karisa J, Chesaro C, Ohuma E, Ignas J, et al. Diarrhoea complicating severe acute malnutrition in Kenyan children: a prospective descriptive study of risk factors and outcome. PLoS One. 2012; 7:e38321.

30. Babirekere-Iriso E, Musoke P, Kekitiinwa A. Bacteraemia in severely malnourished children in an HIV-endemic setting. Ann Trop Paediatr. 2006;26:319-28.
31. Sullivan J, Ndekha M, Maker D, Hotz C, Manary MJ. The quality of the diet in Malawian children with kwashiorkor and marasmus. Matern Child Nutr. 2006;2:114-22.

32. Gopalan C. Kwashiorkor and marasmus: evolution and distinguishing features. 1968. Natl Med J India. 1992;5:145-51.

33. Prentice AM, Moore SE, Fulford AJ. Growth faltering in low-income countries. World Rev Nutr Diet. 2013;106:90-9.

\section{Submit your next manuscript to BioMed Central and take full advantage of:}

- Convenient online submission

- Thorough peer review

- No space constraints or color figure charges

- Immediate publication on acceptance

- Inclusion in PubMed, CAS, Scopus and Google Scholar

- Research which is freely available for redistribution 